\title{
Representación social de la fuerza policial de la Ciudad de San Luis sobre el Colectivo Trans y su relación con el discurso dominante ${ }^{1}$
}

\author{
Yessica Alejandra Ortiz Alarcón ${ }^{2}$ \\ Universidad Nacional de San Luis
}

\section{Aporte de Estudiante}

Resumen: Este aporte tiene por objetivo analizar las representaciones sociales de los integrantes de las fuerzas policiales de la Ciudad de San Luis, Provincia de San Luis, sobre el Colectivo Trans. Asimismo, se establece el vínculo que existe entre esas representaciones y los discursos dominantes sobre el género y las sexualidades. Para cumplir con esos propósitos se acude a un enfoque cualitativo en donde predominan técnicas de recolección de datos tales como cuestionarios abiertos y entrevistas semi-estructuradas. Los resultados muestran que los miembros de las fuerzas policiales identifican como trabajo predominante del Colectivo Trans el ejercicio de la prostitución, aunque algunos señalan otros tipos de trabajos enmarcados en la formalidad laboral. Por otra parte, las representaciones develan una feminización de lo trans, ya que los varones trans son escasamente identificados como tales. Esas asociaciones del trabajo del colectivo con otras tareas que no son el ejercicio de la prostitución constituyen fugas de sentido respecto del discurso dominante.

Este trabajo se inserta en un proyecto de investigación de la Facultad de Psicología de la Universidad Nacional de San Luis denominado "Derechos Humanos, Control Social y Sectores Vulnerables". Asimismo, el trabajo de la tesis final de grado de la autora se realiza sobre este tema.

\section{Introducción}

Dentro de los ejes que se analizan en el marco del proyecto de investigación antes mencionado uno es el que refiere al Colectivo Trans y las construcciones sociales alrededor de este.

Un sector tenido en cuenta para indagar dichas construcciones fue la fuerza policial dada su calidad de control social, siendo que vehiculiza el ejercicio legal y ejerce la fuerza física legítima por parte del Estado. Además, es interesante su perspectiva porque si bien está interactuando con el mundo civil permanentemente, se rige bajo sus propias reglas. Esto no es menor puesto que, siguiendo a Sirimarco (2012), el creciente interés por esta institución

\footnotetext{
1 Una versión preliminar de este trabajo fue presentada en las XXV Jornadas de Jóvenes Investigadores AUGM 2017.

2 Estudiante avanzada de la Lic. en Psicología de la Universidad Nacional de San Luis. Correo electrónico: yalejandra.ortiz@gmail.com
} 
radica en que para ciertos sectores la policía se ha convertido en un objeto de investigación no sólo válido, sino también políticamente necesario.

El presente artículo desarrollará un análisis realizado sobre las representaciones sociales de 123 agentes policiales de la Provincia de San Luis, con relación a la/s actividad/es que ocupan a las personas trans, tomando en cuenta datos obtenidos de entrevistas semiestructuradas realizadas a agentes policiales y a un miembro del Colectivo Trans.

El objetivo principal de esta investigación es el de reflexionar sobre las representaciones sociales que sostienen los/as agentes de policía hacia la actividad predominante del Colectivo Trans. En este sentido, los análisis que acá se plasman se han realizado teniendo en cuenta una perspectiva de género, y en relación con los últimos avances legislativos en el país, los cuales procuran el cumplimiento de derechos para dicho colectivo.

\section{Análisis}

Lo primero que se observó fue que los/as oficiales de policía plantearon tres maneras de contacto con personas del Colectivo Trans. La primera interacción refiere al ejercicio de la prostitución y a las denuncias que realizan personas del Colectivo Trans debido a maltratos por altercados en la vía pública; la segunda forma de contacto que expresaron fue por medio de la atención que realizan las comisarías para la realización de trámites. La tercera refiere a cuatro respuestas obtenidas donde las interacciones se realizan por fuera del ámbito laboral.

Posteriormente, se procedió a profundizar sobre la pregunta ¿Cuál piensa usted que es la actividad predominante de las personas trans? Y frente a las respuestas se realizó la construcción de las siguientes categorías: Actividad Predominante, el Porqué de la Actividad Predominante y si ésta constituye un Riesgo.

Los resultados más contundentes fueron: el $63 \%$ de los/as oficiales respondieron que la prostitución era la actividad predominante de las personas trans; el 27,4\% consideraron también a la prostitución como actividad predominante pero contemplaron otras tales como panadería, peluquería y venta de ropa; y el otro 19\% plantearon la inserción laboral debido a planes sociales y actividades relacionadas a la salud, a la educación y a la atención al público.

Es así que el $90 \%$ de los resultados se refirieron a la prostitución vinculada con las mujeres trans. Es relevante puntualizar que sólo dos de los/as agentes policiales hicieron alusión al reconocimiento de varones trans. Esto podría indicar que en lo que se refiere a la fuerza policial, la representación social de dicho colectivo está concebida por personas con un género auto-percibido de carácter femenino. En este punto, merece ser retomada una 
respuesta textual para reflexionar, donde se le pregunta a un agente si alguna vez ha tenido contacto con dicho colectivo:

No, nunca. No sé si te servirá, pero una vez atendí a una chica que se sentía chico, o sea se vestía como chico y todo pero era una chica. Vino a hacer una denuncia con la madre porque le habían pegado y la madre decía -a ella le pegaron así, a ella le pegaron, a ella- y yo decía ¿a ella quién? Yo le pregunté en un momento, ¿Dónde está tu hija? Y me dice -ella- señalando al que parecía un chico (...) (Anónimo, comunicación personal, junio de 2015).

Acá se observa que el entrevistado respondió ante la pregunta dudando si su situación podía enmarcarse como contacto con una persona trans. Esto podría dar cuenta de cómo se dificulta salir de la representación, la cual se basa en que el Colectivo Trans sólo lo componen personas de género auto-percibido femenino.

También puede observarse cómo la feminización del Colectivo Trans repite la idea de vulnerabilidad de las mujeres. Esto lo daría cuenta la representación de su actividad predominante como lo es la prostitución. Se plantea al respecto que:

La vulnerabilidad de las mujeres, es, así pues, el resultado de una posición en la estructura social (...) que facilita recibir los efectos negativos del funcionamiento de la sociedad, sea en términos de pobreza (feminización de la pobreza), sea en términos de violencia (violencia de género). A esto se une la idea de discriminación, resultado de una relación estructural entre, por lo menos, dos actores (Tortosa, 2009, p.83).

Lo anterior podría constatarse con la asociación que realizaron los/as agentes de policía de las mujeres trans con una actividad escasamente reconocida socialmente, marginada y criminalizada como lo es la prostitución.

Se realizó una entrevista a un varón trans, quien es un reconocido referente de militancia en la Ciudad de San Luis. Cuando se le preguntó si hubo cambios cuando decidió reconocer públicamente su identidad, respondió:

Nosotros, los chicos trans pasamos muy desapercibidos (...) Las chicas trans no, tienen vello facial, tienen otras cosas que no pueden (...) y bueno y el tema de la sociedad que ya es machista y bueno, es un maricón y no sé. He llegado a escuchar puto con peluca o un montón de cosas así. Son muchísimas 
más violentas las cosas que han vivido, ellas (...) (Anónimo, comunicación personal, 6 de junio de 2016).

Hasta acá se pueden destacar por lo menos dos cuestiones importantes. La primera tiene que ver con cómo el pensamiento hegemónico subvaloraría las categorías feminizadas, donde se seguiría considerando al "cuerpo y roles femeninos como lo diferente, inferior y disimétrico de lo masculino" (Expósito, 2011, p. 96).

De esta manera puede observarse que la institución policial replicaría el discurso androcéntrico dominante del cual se desprende la representación de actividad predominante de las mujeres trans. Esto confirmaría pues que "en realidad, sólo en la sociedad contractual la mujer queda protegida por la misma ley que rige las relaciones entre hombres en tanto sujetos de derecho sin embargo, (...) la estructura de género nunca adquiere un carácter completamente contractual"' (Segato, 2003, p. 29).

La segunda cuestión, remite a que los varones trans no serían concebidos como parte del colectivo. De acuerdo con lo que se ha reflexionado hasta acá queda como posterior análisis la pregunta de si tal invisibilización puede deberse a una pseudo aceptación social implícita donde lo masculino está más aceptado, o inquieta en menor medida.

Otra de las preguntas que se realizaron tuvo que ver con los motivos que llevaban a efectuar dicha actividad que los/as policías habían planteado como predominante, con lo cual surgieron las siguientes categorías: Por Necesidad (que además incluye por falta de salida laboral y discriminación) 66,3\% y por Opción/Elección 8,1\%.

Como se puede observar, las respuestas apuntan a la noción de que dicha actividad no es elegida. Una de las personas que fue entrevistada expresa:

La prostitución por la discriminación de la sociedad. No es que no tengan mucha voluntad de trabajar, pero no se le abren muchas puertas. Contratar a un travesti en un negocio habla de la imagen del negocio o no les cae muy bien a los clientes, pienso yo (Anónimo, comunicación personal, junio de 2015).

Y como esta, muchas de las respuestas expresarían una desventaja social que detenta el discurso patriarcal para las trans femeninas. No es intención en este artículo debatir si la prostitución es un trabajo o no, pero es preciso destacar que en las entrevistas es concebida como una actividad que pone de manifiesto la precarización, producto de la exclusión social por medio de la marginalización de los cuerpos feminizados. 


\section{Conclusiones}

Es importante destacar que las relaciones de género están aún enmarcadas dentro de una estructura de poder que expresa una demarcación de posicionamientos jerárquicos y de valores diferenciados (Segato, 2003). Es así como las masculinidades hegemónicas siguen estando dentro del escalamiento social en un lugar privilegiado a expensas de la subordinación de otras identidades.

Esto podría evidenciarse en que las modalidades de subordinación siguen siendo la feminización de los cuerpos, no sólo desde las palabras o frases ya tan naturalizadas socialmente como "mariquita" o "nenita", sino desde la vulneración de los derechos formalizados en los papeles, pero deslegitimados socialmente.

Sin embargo, es un proceso que ya está en marcha, subvirtiendo poco a poco las ideas hegemónicas instituidas. Esto podría observarse, por ejemplo, en que algunas de las respuestas respecto a las actividades predominantes tenían que ver con la formalidad y en ello con alguna garantía de una vida digna.

\section{Referencias bibliográficas}

Expósito García, M. (2011). El cuerpo desnudo: cuerpos equivocados y cuerpos que no hablan. Cuadernos Kóre. Revista de historia y pensamiento de género, 1, 79-96.

Segato, L. (2003). La estructura de género y el mandato de violación. En Las estructuras elementales de la violencia (pp. 21-54). Buenos Aires: Universidad Nacional de Quilmes Editorial.

Sirimarco, M., Galeano, D. (2012) ¿Cómo pensar la policía desde la academia? Red de Periodistas Judiciales de Latinoamérica. Recuperado de: www.cosecharoja.org

Tortosa J. M. (2009). Feminización de la pobreza y perspectiva de género. Revista Internacional de Organizaciones, 3, 71-89. 